\title{
Assessment of a Collaborative NSF RET Program Focused on Advanced Man- ufacturing and Materials
}

\section{Dr. Margaret Pinnell, University of Dayton}

Dr. Margaret Pinnell is the Associate Dean for Faculty and Staff Development in the school of engineering and associate professor in the Department of Mechanical and Aerospace Engineering at the University of Dayton. She teaches undergraduate and graduate materials related courses including Introduction to Materials, Materials Laboratory, Engineering Innovation, Biomaterials and Engineering Design and Appropriate Technology (ETHOS). She was director of the (Engineers in Technical Humanitarian Opportunities of Service-Learning) for approximately ten years. She has incorporated service-learning projects into her classes and laboratories since she started teaching in 2000. Her research interests include community engaged learning and pedagogy, K-12 outreach, biomaterials and materials testing and analysis.

Ms. Melissa Rose Taylor, University of Dayton

Dr. Ahsan Mian, Wright State Unviersity

Ahsan Mian received the B.S. and M.S. degrees in mechanical engineering from Bangladesh University of Engineering and Technology (BUET), Bangladesh, the M.S. degree in mechanical engineering from Tuskegee University, Tuskegee, AL, and the Ph.D. degree in mechanical engineering from Auburn University, Auburn, AL in 2000. Ahsan Mian joined the Department of Mechanical and Materials Engineering in the College of Engineering and Computer Science at Wright State University (WSU) as an Associate Professor in January 2013. He was an Associate Professor of Mechanical Engineering at Montana State University (MSU), Bozeman, Montana prior to joining WSU. He was a faculty member of MSU from August 2005 to December 2012. From 2002 to 2005, he was a visiting faculty member in the Mechanical Engineering Department of Wayne State University. From 2000 to 2002, Dr. Mian worked as a designer for Visteon Corporation's automotive electronics division located in Dearborn, Michigan. He also served as a faculty member in the Department of Mechanical Engineering, BUET from 1988 to 1993. Dr. Mian's research interests include advanced manufacturing; silicon micro-fabrication; microelectromechanical Systems (MEMS); and electronic and MEMS Packaging. He has authored over 85 technical publications, book chapter, and is a member of the American Society of Mechanical Engineers, American Society of Engineering Education, and Phi Kappa Phi. Dr. Mian is a recipient of MSU President's Pure Gold Award (2012), ASEE Multidisciplinary Engineering Division Best Paper Award (ASEE Conference 2011), IMAPS Conference Best Paper Award (1999), and Graduate Research Forum Award (1998).

\section{Mrs. Sandra M Preiss, Dayton Regional STEM Center}

Sandra Preiss, is the Coordinator for the Dayton Regional STEM Center. She has served the STEM Center since December 2008 in various capacities. Her current role includes operational management; program management; innovation management; educator professional development; and curriculum generation and editing. Sandra, a licensed high school science educator, has taught in academic and informal educational settings ranging from early childhood through high school.

Dr. Leanne Petry, Central State University

Dr. M. Suzanne Franco

Wright State University 


\title{
Assessment of a Collaborative NSF RET Program Focused on Advanced Manufacturing and Materials
}

\begin{abstract}
Manufacturing is a key pillar to economic vitality and growth in the United States (US). However, the US faces increasing competition in the area of manufacturing from across the globe. As such, the future of the US's role in manufacturing requires innovation, cutting-edge and sustainable technologies, and new materials. Furthermore, this new era of manufacturing will require a well-educated and well-prepared STEM workforce. Since the task of inspiring and preparing K-12 students in STEM falls largely on K-12 teachers, it is critical that the teachers understand the role of materials and manufacturing in the US and are provided with the tools and knowledge that will empower them to get children excited about STEM as well as careers in materials and advanced manufacturing. The main objective of the Collaborative Research Experience for Teachers Program entitled Inspiring The Next Generation of a Highly-Skilled Workforce in Advanced Manufacturing and Materials was to provide current and future middle and high school teachers with the skills required to successfully engage their students in STEM learning experiences by immersing these teachers in real-world engineering research that was thematically centered around materials and advanced manufacturing. This collaborative RET site placed teachers and pre-service teachers with research mentors at one of three regional universities to work on engineering research projects that connect with regional strengths in advanced manufacturing and materials. Participating teachers and pre-service teachers joined other professionals in the region in an immersive materials "boot camp" facilitated by ASM prior to the start of their research experience. Field trips, guest speakers and group work that produced K-12 curriculum complemented the teams' research experience. During the culminating activities, the groups presented the STEM curriculum developed, the final laboratory project results and provided regular guided reflections regarding their efforts during the six-week program. Local System Change (LSC), Mathematics Teaching Efficacy and Beliefs Instrument (MTEBI) and Science Teaching Efficacy and Beliefs Instrument (STEBI) surveys were administered to identify changes in attitudes, beliefs and practices. Results of the evaluation suggest that this collaborative RET program was successful at meeting a majority of its nine objectives. Evaluation data shows that there was no significant changes at the 0.05 level in the teachers' responses to the MTEBI or STEBI. For the LSC, teacher responses were significantly higher at the 0.01 level for attitudes towards teaching. Feedback obtained from the teachers will be used to modify the program for the next cohort.
\end{abstract}

\section{Introduction}

A 2010 report for the National Association of Manufacturers and the NAM Council of Manufacturing Associations states, "America's manufacturing innovation process is vital to promoting economic growth, productivity gains and increases in our standard of living." The 
authors go on to explain that, "An increment to manufacturing production in the U.S. creates more economic activity both within and outside the sector than does a similar increment in any other major sector. Historically, manufacturing's innovations and investment raised its productivity faster than other large sectors and its productivity has added substantially to overall U.S. productivity." 1 Similarly, in an article published in Time Business and Money Magazine (2013), the authors report, "The new economics of Made in the USA are built in large part around acquiring cutting-edge technologies ahead of global competitors and then using those new techniques to produce more efficiently on super-automated factory floors." " It is strongly believed that manufacturing will once again become a local industry as the products will be manufactured near raw materials or markets. Furthermore, future global dominance in manufacturing will depend upon the development and adoption of cutting-edge manufacturing technologies including robotics, artificial intelligence (AI), 3D printing, and nanotechnology. ${ }^{3}$ There is a tremendous push from both federal and industrial entities to speed up the maturation of manufacturing technology. New institutes such as the National Additive Manufacturing Innovation Institute (NAMII), now called America Makes, located in Youngstown, Ohio, have been created from federal initiatives in an effort to reinvigorate the US manufacturing industry and jobs market and to promote innovation and collaboration in cutting-edge manufacturing technologies. ${ }^{4-7}$ Additionally, federal agencies such as the National Science Foundation (NSF) are sponsoring workshops and forums such as the NSF Workshop on Future Research Needs in Advanced Manufacturing and the NSF Workshop on Additive Manufacturing to discuss issues and developments associated with manufacturing. ${ }^{8,9}$ To complement this new era of manufacturing, engineers and scientists are also developing new types of materials that are compatible with the manufacturing techniques and are stronger, lighter, more energy-efficient, and more durable than currently available materials. As such, the future of the US' role in manufacturing is highly dependent on innovation in materials and manufacturing as well as the adoption of advanced and sustainable manufacturing technologies. ${ }^{3}$

This new era of manufacturing will require a well-educated and well prepared STEM workforce. Unfortunately, the US will not be able to meet these workforce goals unless we are able to broaden participation by inspiring our youth to pursue STEM disciplines. ${ }^{10-16}$ The Society of Manufacturing Engineers (SME) states in a 2012 report, "If the United States is to maintain its leadership in manufacturing - a sector that contributes greatly to the health of the overall economy...the crisis in STEM and manufacturing education must be corrected." ${ }^{17}$ Since the task of inspiring and preparing K-12 students in STEM falls largely on K-12 teachers, it is critical that teachers are provided with the tools and knowledge to accomplish this task. Unfortunately, most K-12 teachers have little understanding about materials and the role they play in society. ${ }^{18,19}$ Furthermore, many people have significant misconceptions about manufacturing in the US. ${ }^{16}$ In a 2008 report summarizing the outcomes of The Workshop on Materials Science and Materials Engineering Education sponsored by the NSF, recommendations were made that include providing training and professional development for K-12 teachers to help them better 
understand materials concepts and applications, modifying existing teacher training programs to include information about materials and manufacturing careers and developing outreach tools for students that demonstrate the critical role that materials and manufacturing play in modern society. ${ }^{18}$

Ohio was particularly hard hit by the Great Recession and this was due in part to its reliance on manufacturing. About 34\% of the approximately 117,000 jobs lost in Ohio between 2007 and 2011 were in the manufacturing sector. Despite this, according to Economic Analyst, George Zeller, "Manufacturing is driving the Ohio recovery, particularly since we have such an intense concentration [of jobs in the sector]. Manufacturing is not only important for its high-wage jobs for Ohio workers, but it is also extremely important because of its large ripple effect on the rest of the economy." ${ }^{20}$ In particular, the Dayton Region has a long history of engineering innovation in manufacturing and also serves as the home to organizations that are heavily invested in materials and manufacturing research. Among these is The Air Force Research Laboratory's (AFRL) Materials and Manufacturing Directorate located at Wright-Patterson Air Force base which develops materials, processes, and advanced manufacturing technologies. ${ }^{21}$ Additionally, the Dayton Region is one of the largest tooling, machining and material processing centers in the U.S and manufacturing contributes to more than $14 \%$ of the Region's workforce. ${ }^{22,23}$ Additionally, advanced manufacturing and materials has been identified by top governmental officials as well as academic institutions and centers as being a key regional cluster. ${ }^{3,24}$ The importance of these regional clusters cannot be underemphasized. The US Department of Commerce states, "Regional clusters can be thought of as an 'innovation ecosystem' that 'is made up of communities of people with different types of expertise and skill sets." 25 As such, the Dayton Region is particularly interested in growing its STEM workforce and inspiring K-12 students to consider careers in materials and advanced manufacturing.

In 2014, three universities in the Dayton Region, Central State University (CSU), University of Dayton (UD) and Wright State University (WSU), received a grant from the NSF to provide research opportunities to K-12 teachers through a Research Experience for Teachers (RET) award. The overarching goals of the NSF RET program are to develop long-term, collaborative relationships with K-12 teachers and university faculty, involve K-12 teachers in engineering research and help teachers translate this research into classroom activities. ${ }^{26}$ In addition to these overarching goals, the main objective of this project entitled: Inspiring The Next Generation of a Highly-Skilled Workforce in Advanced Manufacturing and Materials was to provide current and future middle and high school (G6-12) teachers with the skills required to successfully engage their students in STEM learning experiences by immersing these teachers in real-world engineering research thematically centered around materials and advanced manufacturing. By training teachers through this research experience, it is hoped that the participating teachers will be better equipped with knowledge, skills, curriculum and resources to affect broad-scale change 
in instructional practices linked to advanced manufacturing and materials and 21 st century STEM skills.

\section{Program Design and Objectives}

The Inspiring the Next Generation of a Highly-Skilled Workforce in Advanced Manufacturing and Materials program used materials and advanced manufacturing as the focus for the teacher research experiences in engineering. The advanced manufacturing and materials focus was selected based on the aforementioned regional needs and strengths in addition to the fact that all three participating universities have strengths in this area. Specifically the main objectives of this program were to:

- Transfer the program's team-based applied engineering research activities into the teacher participants' classrooms through experience and the development and dissemination of new curriculum associated with these activities;

- Provide the teacher participants with new knowledge of engineering disciplines and careers, particularly those related to advanced manufacturing and materials and generate a new appreciation for the value of diverse team-based learning environments; and

- Provide the participants with beneficial professional development activities integrated into the RET programming

Additionally, the participants were provided with exposure to three regional universities that represent a smaller ( 1800 students) public HBCU (CSU), a mid-size ( 8,000 students) private (UD) and a mid-size ( 17,000 students) public (WSU) university.

During its pilot year, this program placed twelve G6-12 teachers and five pre-service teachers with research mentors at one of the three regional universities to work on projects that connected with regional strengths in materials and advanced manufacturing. Teachers and pre-service teacher participants were required to attend an orientation meeting prior to the start of the program. During this orientation, the participants were able to meet their team members, interact with research mentors and project PI's from the three universities, fill out required paperwork and engage in some ice-breakers and simple design activities. The participants were provided with program logistic information, a calendar of activities and lab safety instruction.

The six-week program started at the end of June and began with a week-long materials boot camp facilitated in conjunction with the ASM Educational Foundation. During this week, the RET participants joined other teachers in the area to participate in the ASM Materials Camp for Teachers that was held at CSU. The goal of this camp was to provide the RET participants with background information on materials and manufacturing and prepare them for lab-based work with their research mentors. Through this experience, the participants had the opportunity to engage in hands-on work with metals, ceramics, polymers and composites, and to develop a greater appreciation for the importance of these materials in modern life. Additionally, the participants were provided with curricular tools and ready-made materials activities, supplies 
needed to replicate some of the classroom activities, a one-year membership in ASM and the opportunity to network with teachers and engineers beyond just those involved in the RET.

During the remaining five weeks, the RET participants were placed on research teams to work on their projects. Each of the six research teams were made up of two practicing teachers and a research mentor. Five of the six teams included one pre-service teacher as well. The program was designed so that each of the three universities hosted two teams. Each team engaged in laboratory experiments in state-of-the-art research facilities under the guidance of their assigned research mentor at their host university. All of the research projects focused on advanced manufacturing and materials and included:

- Natural and Azo Dyes: Effect of pH on Color Process and Application - CSU

- Natural and Synthetic Dyes: Application to Fibers and Bioplastics - CSU

- Tensile Properties of 3D Printed Materials - Two teams - UD

- Influence of Machine Variability on Mechanical Properties of 3D Printed Polymeric Materials - WSU

- Mechanical and Physical Characterization of 3-D Printed Conductive Polymers - WSU

During these five weeks, the RET participants spent three to four days per week in the lab at their host university working on their projects and the remainder of the time engaged in curriculum development, industry tours or other professional development activities. Among these professional development activities included instruction on conducting effective literature reviews and participation in a "Changing the Conversation" activity to provide the RET participants with ideas on how to attract a more diverse group of students to the field of engineering. ${ }^{27,28}$ Additionally, each week, the RET participants were exposed to innovative research and activities in the greater Dayton Region through a weekly speaker series facilitated by regional engineers and scientists currently working on cutting-edge research in the area of materials and advanced manufacturing.

\section{Curriculum Development}

Since one of the main objectives of this program was to facilitate the transfer of the engineering research activities into the teacher participants' classrooms, a significant component of the experience was dedicated to curriculum development. As such, the teachers and pre-service teachers participated in facilitated workshops and activities that focused on curriculum development and inquiry-based learning. The teachers and pre-service teachers, with input from their research mentors, the project PI's and a curriculum development coordinator, developed and wrote STEM curriculum that incorporated some of the concepts that they had learned from either the ASM Materials Camp or from their research experience. Additionally, all of the curriculum was designed to align with the state curriculum standards. To facilitate this process, the program participants made use of a well-established, research-based curriculum template. ${ }^{29-31}$ During a Curriculum Sharing Day held at CSU, each team had the opportunity to share the 
curriculum they developed with the rest of the participants and invited guests. Each team was required to provide an overview of their lesson and then facilitate a short sample hands-on activity. A question and answer period was facilitated at the end of each teams' presentations which provided the audience with an opportunity to provide feedback and give ideas to the presenting team. The curriculum developed through this experience is currently being subjected to a vetting, editing and piloting process and will eventually be published on the Dayton Regional Stem Center (DRSC) website, where it can be widely accessed and used by teachers across the nation. A summary of the curriculum developed as a result of the RET experience is summarized below:

Haul'n Oats - Targeted Grades: 8 th $-9^{\text {th }}$ Engineering Design Challenge: A packaging company is concerned with being more energy efficient and have hired you to move their product across their factory. They are packaging oatmeal for two different brands, one that has a cylindrical container and one that is packaged in a box. The product is packaged on the second floor and they need to move it to a quality checkpoint on the first floor of the same room in their factory. Then it must move through an elevated hole in that room to a second room of their factory and get to a shipping point on the first floor of the second room. Your team will build a transport prototype used to move both payloads as energy efficiently and quickly as possible.

Whoops! Here we go! - Targeted Grade: $9^{\text {th }}$ Engineering Design Challenge: Students will design a cell phone case incorporating geometric design and properties of matter that will protect a piece of glass representing their cell phone during lab testing. In order to test their designs the students will be doing a drop test 3 meters above ground. The students will have the opportunity to re-design after initial testing. Students will be given the opportunity to tweak their design after completing stations and receiving feedback from their peers.

Stick It! - Targeted Grade: $\mathbf{9}^{\text {th }}$ Engineering Design Challenge: After an investigation of various geometric structures and their associated strength properties, students will work collaboratively to design the internal structure of a hockey stick for a new school sledge hockey team. They would like you to test the normal tension force strength and flexure associated with various types of materials used in the sledge hockey stick. They have requested you to provide them with a brief presentation on your findings.

Swiss Sled Emergency!- Targeted Grade: $5^{\text {th }}$ Engineering Design Challenge: Students will be presented with a sled design challenge. Students will work in groups to research the problem at hand and develop 3 possible solutions for their sled design and materials to be used. They will then choose one prototype that will have the greatest speed, go the farthest distance, and pass safety testing. Students will build their prototype and begin testing on the ramp given. They will be given the opportunity to redesign their prototype to increase performance. Students will record results from their testing. The groups will create graphs that depict their data and find the average speed, distance traveled, and safety rating for their prototype. Students will share their findings with the class.

Dyeing to Design - Targeted Grade - $7^{\text {th }}$ Engineering Design Challenge: A family has a threeyear old child and is expecting a new baby. They want to decorate the toddler's new bedroom. They have a fabric sample from a quilt they want to use on the toddler's bed, and would like the room's colors to match. They are asking you to create a design pitch showing at least two different 
materials colored to match with their fabric sample. Since there is a new baby on the way, they would like the materials to be natural and safe if ingested. To help with reproduction of colors on a larger scale for the room, they are requesting to have the colorant (solute), solvent, concentration and absorbance levels, and other physical and chemical properties of the dyes used.

Change Your Mood, Change Your Color - Targeted Grade: $7^{\text {th }}$ Engineering Design Challenge: Members of the board of a local children's hospital are investigating ways to better serve their patients. Currently, the walls of the hospital are tan and do not account for patient preference. Board members have requested your assistance in designing and developing a paint prototype that has the ability to change color based on patient preference. Their ultimate hope is to provide their patients a little control in what typically is an uncontrollable situation. The Board has also requested a brief multimedia presentation and demonstration of the proposed paint prototype.

Upon completion of the six-week experience, practicing RET teachers were selected to either continue working on curriculum development through the DRSC STEM Fellow Program or to pilot additional STEM lessons as a STEM Ambassador.

\section{Program Assessment}

The objectives of this program are being assessed both qualitatively and quantitatively. The sources used to evaluate progress towards meeting the program objectives were teacher responses to reflective survey questions; pre-program surveys about teacher attitudes, beliefs and practices; work with DRSC during the follow-up academic year; and post-program surveys that were administered in December of 2015. The program participants completed five reflections/surveys during the six-week program. The questions were developed based on the grant objectives and specific activities. The evaluator coded the reflections with ID numbers to remove participant identification, and participants were advised that their responses would remain anonymous. The questions were developed based on the grant objectives and specific activities. Additionally, all practicing teacher participants completed Horizon, Inc.'s Local Systemic Change (LSC) survey during the first week of the program and in December of $2015 .{ }^{32}$ The LSC teacher questionnaire tracks systemic change in teachers' attitudes and perceptions regarding their mathematics and/or science content preparedness, pedagogical preparedness, classroom practices, and principal support for math and science teaching. For the cohort, changes in the attitudes towards teaching were significantly higher at the 0.01 level. Math teacher participants completed the Mathematics Teaching Efficacy and Belief Instrument or MTEBI. ${ }^{33}$ Science teacher participants completed the Science Teaching Efficacy and Belief Instrument or STEBI during the first week of the program and again in December of 2015. ${ }^{34}$ Both the MTEBI and STEBI collect information about the teachers' self-efficacy and expected student outcomes. ${ }^{34}$ For the 2015 cohort changes in the Math and Science teachers' self-efficacy and expected student outcomes were not significant at the 0.05 level. 
Results of the evaluations obtained as of January 2016 were mapped to the detailed program objectives and are summarized below. Recommendations for adjustments are included at the end of each objective summary.

Objective A: Teach engineering concepts to over 1,000 K-12 students over the project period, including students from schools with a significant minority population: Participants represented twelve different rural, urban and suburban Grade 5-12 schools. These schools have a percentage of students on free/reduced lunch that ranges from $4.3 \%$ to $100 \%$ and a non-white population that ranges from less than $1 \%$ to greater than $95 \%$. In an effort to increase the impact to minority serving schools, targeted recruiting will be done for the 2016 cohort.

Objective B: Develop inquiry- and team-based STEM curriculum and innovative pedagogy to encourage interest in STEM and, in particular, engineering: Participants worked on using innovative ways to design curriculum that incorporated the interrelatedness of different topics and were challenging for students. They also learned to construct weekly lesson plans to enhance the educational process. Teachers aimed to include different aspects of their training while developing the STEM curriculum.

Our curriculum relates to our experiences in our research through the use of different materials for different purposes. We are testing materials for their strength by tensile testing. Our curriculum is based on having the students create a sled that will be designed to go the fastest, longest distance, and safest. Students will need to use different materials for their desired result.

We have an introduction to 3-D printing in our curriculum and properties of matter.

I learned how to make lesson plan based on Ohio curriculum. Using the scientific method to teach students in class that become advance engineering ways such as Engineering design challenge, what is a big idea, knowledge, instructional process, and career connection

No recommendations were made for program modification in regards to this objective.

Objective C: Disseminate curriculum deliverables through the DRSC website and professional development workshops such as the STEM Think Tank: The curriculum will be available on the DRSC website once it has been through a thorough vetting, piloting and editing process. Additionally, this curriculum will be included in professional development workshops facilitated through the DRSC. The results of this will likely not be available until the fall of 2016. As such, it is recommended that statistics be kept regarding piloting and usage of curriculum deliverables during the follow-up academic year.

Objective D: Spark the interest of the participants in STEM by providing them with the opportunity to use modern engineering tools and to gain new knowledge of engineering: Participants had the opportunity to learn about 3D printing, visit a Kodak factory, measure the 
wavelength of light, use a propane torch, learn about specific structures of different materials, and gain hands-on experience using modern technology. They also learned about new career opportunities in the field of engineering.

I learned about the different additive manufacturing (3D printing) methods, and learned about the FDM machines that we would be using to create the samples for our tests. We were taught how to use the Insight program to create computer models of the samples that we would be printing and why the orientation of the sample is important. We researched the testing specifications and the materials that we would use. We toured the facilities and saw some of the machines that we would be using for our testing.

I have learned about many different engineering careers that do not require a four year degree, including forging. I thought it was very nice to have to speaker come in and talk about his company because he not only provided a lot of information but he also offered for us, as teachers, to bring in our students for tours of the company. I enjoyed designing and testing a product that was new and cutting edge (nano-carbons parts made on a $3 D$ printer that may later be used for electronics). It is nice to learn while being on the forefront of this research.

In the lab we were given free range to create these dyes using the given knowledge. We were then encouraged to try new procedures that could result in new dyes. This was satisfying because it gave me a sense of autonomy but was scaffold in a way that made us want to keep trying new ideas.

No recommendations were made for program modification in regards to this objective.

Objective E: Understand the social relevance and ethical implications of engineering activities related to manufacturing (human rights, environmental impact, etc.): Unfortunately, the social relevance and ethical implications of engineering was addressed minimally during the industry tours. However, through the weekly speaker series facilitated by regional engineers and scientists currently working on cutting-edge research in the area of materials and advanced manufacturing, one presentation discussed the social responsibility of engineering. It was specifically noted that the engineer is to be a steward of the developed technology with the aim to be the betterment of humankind. . The program will be modified for the 2016 cohort to more explicitly include a discussion of these topics during industry tours. Specifically, feedback will be requested regarding aspects of social relevance and ethics in each industry visit and laboratory experience.

Objective F: Share knowledge, ideas and concepts working on teams with professional and preservice teachers, research mentors and industry partners. Participants interacted with engineers and other professionals as a part of their training experience. They also had the opportunity to collaborate with colleagues from other programs and work in groups in the research laboratories and while developing curriculums. Teachers expressed that the experience was helpful for most of them, with the exception being teams at one site reporting initial research organization contributed to initial programming frustration that was resolved with the first week of research. 
I really appreciate the team that I am working with. The team of teachers that I am working with is great people who all work well together. I also appreciate the team of professors and mentors that are working with us a UD. They are very helpful and great to work with. The experience has been nothing but positive for me.

Meeting STEM professionals has made this experience very satisfying and will strengthen my ability to have career discourse with my students.

In an effort to minimize the frustrations, program modifications, including developing a more detailed research plan in conjunction with the research mentors will be implemented for the 2016 cohort.

Objective G: Acquire collaboration and networking possibilities through interaction with realworld engineering industry and government mentors and partners: Teachers had the opportunity to interact and network with professionals from different fields.

I found it very interesting to actually see various parts of the printers at Kodak. Anyone can tell you about the process or the machines that are printing but it is a completely different experience to be where it is occurring and see the parts in action. I also thought it was very interesting to see the lab where the various colors of ink are made. At this tour we were able to see the actual printers and learn about the history of Kodak.

Throughout the NSF-RET summer program our group has worked so well together at solving issues that came up and celebrating in successes. Each member truly works well together in the communication and collaboration of our research. This whole program has been satisfying.

The most satisfying experience has been working with the other team members in our group. We have overcome typical research problems by working together, and have managed to have some fun doing it.

No recommendations were made for program modification in regards to this objective.

Objective H: Attain leadership roles in K-12 setting through the RET program's professional development component: Since the participants only recently completed this program, no significant data has been collected yet to determine if this objective was met. However, one of the participants participated in the 2015 Forum: Next Generation STEM Learning for All held on November 9, 2015 in Washington D.C. ${ }^{35}$ Four participants also presented their research at the Dayton Engineering and Science Symposium held in November 2, 2015 at Wright State University and all of the participants will have the opportunity to present at the annual Dayton Section of the American Chemical Society that will be held at the University of Dayton in the spring of 2016. ${ }^{36}$ The participants' engagement in professional development and leadership activities will continue to be gathered during the follow-up year.

Objective I: Achieve long-term collaborative partnerships with the regional university research community, engineering professionals, and the DRSC through substantial follow-up activities: Although there is evidence to suggest that relationships were developed, in an effort to better 
assess if these relationships are truly "long-term" relationships, follow-up surveys will be facilitated during the follow-up year and beyond.

\section{Summary}

The pilot year for the Inspiring the Next Generation of a Highly-Skilled Workforce in Advanced Manufacturing and Materials program provided an integrated and real-world engineering research experience for twelve in-service and five pre-service teachers. Teams were developed to include the practicing and pre-service teachers and a research mentor and industrial mentor. Initial data suggests that the program was successful at meeting a majority of the stated objectives. The teams engaged in five materials and advanced manufacturing related research projects at three universities. Additionally, the teams worked collaboratively to develop inquirybased and innovation-centered curriculum. The experience was enhanced through a one-week immersive materials boot camp that was held in conjunction with the ASM Materials Camp. Additionally, the participants engaged in materials and manufacturing related field trips and lectures. Currently, the teacher participants are engaging in significant follow-on activities.

Qualitative data suggest that the pilot program was successful at developing collaborative relationships with university faculty, other teachers and engineering professionals. Program participants also attained new content knowledge regarding engineering, materials and manufacturing as well as exposure to numerous modern engineering technologies, techniques and careers. Through this program, six inquiry-based curricula that align with state standards and bring in the concepts related to materials and manufacturing were developed and are currently being piloted. These curricula will eventually be published on a website for wide distribution. Additionally, the participants gained a better understanding of team work and group dynamics which should aid them in facilitating team-based activities in the classroom. Quantitative data gathered reflected significant positive changes at the 0.01 level for attitudes towards teaching..

Results of the evaluations will be used to modify the program for the next cohort. Specifically, the project PI's will work closer with the research mentors to develop a more detailed research plan to ensure that the participants can make the best use of their laboratory time.. Additionally, the program will be modified to more explicitly include these topics related to ethics and social relevance of materials and manufacturing. Targeted recruiting will be done to attract more program participants that serve schools having a larger percentage of student from populations that are under-represented in engineering.

\section{Acknowledgements}

This material is based upon work supported in part by the National Science Foundation under Grant Numbers EEC-1405923, 1405869, 1405950. Any opinions, findings, and conclusions or recommendations expressed in this material are those of the author(s) and do not necessarily reflect the views of the Engineering Information foundation or the National Science Foundation. 


\section{Bibliography}

1. J. Popkin and K. Kobe (2010), Manufacturing Resurgence, A Must for US Prosperity, National Association of Manufacturers and NAM Council of Manufacturing Associates, January, 2010.

2. R. Foroohar and B Saporito (2013), Is the US Manufacturing Renaissance Real?, available at http://business.time.com/2013/03/28/is-the-u-s-manufacturing-renaissance-real/ 3. M. Nash-Hoff (2012), New Technologies Offer Hope for American Manufacturing - Industry Week Article, available at http://www.mrcpa.org/new-technologies-offer-hope-for-american-manufacturing-industry-week-article/. 4. National Additive Manufacturing Innovation Institute website, http://NAMII.org, Accessed Sept. 2013. 5. Taylor, S. (2013). NAMII Rebrands as America Makes. 3D Printing Industry. Com, accessed December 27, 2015.

6. National Additive Manufacturing Innovation Institute (NAMMI), www.manufacturing.gov, accessed Dec. 27, 2015.

7. America Makes, www.americamakes.us, accessed Dec. 27, 2015.

8. NSF Workshop on Future Research Needs in Advanced Manufacturing from Industrial Perspective, August $12-$ 13, 2013, Arlington, VA. Available at http://advancedmanufacturing2013.northwestern.edu/, accessed Sept. 15, 2014.

9. NSF Workshop on Frontiers of Additive Manufacturing Research and Education, July 11 - 12, 2013, Hilton Hotel Gallery Ballroom, Arlington, VA. (http://nsfam.mae.ufl.edu/), accessed Sept. 15, 2014.

10. http://www.nam.org/Issues/Official-Policy-Positions/Human-Resources-Policy/HRP-01-Education-and-theWorkforce.aspx, accessed Sept 15, 2014.

11. Freeman, A., Hrabowski, F. (2012) Broadening Participation in the American STEM Workforce, BioScience, 62(4):325-326.

12. Frantz, T., Siller, T., DeMiranda, M (2011), Pre-Collegiate Factors Influencing the Self-Efficacy of Engineering Students, Journal of Engineering Education, 100 (3), 604-623.

13. Dubetz, T., Wilson, J., (2013). Girls in Engineering, Mathematics and Science, GEMS: A science outreach program for Middle-School Female Students, Journal of STEM Education, 14 (3), 41-47.

14. National Academy of Sciences (2007). Rising Above the Gathering Storm: Energizing and Employing America for a Brighter Economic Future, National Academy of Sciences, National Academy of Engineering, Institute of Medicine, National Academies Press, available at http://www.nap.edu/catalog/11463/rising-above-the-gatheringstorm-energizing-and-employing-america-for, accessed December 21, 2015.

15. Chandler, J., Fontenot, A., Tate, D., (2011). Problems Associated with a Lack of Cohesive Policy in K-12 Precollege Engineering, Journal of Pre-College Engineering Education Research (J-PEER), 1 (5) http://dx.doi.org/ $10.7771 / 2157-9288.1029$

16. Jack, H. (2004), Increasing Manufacturing Engineering Enrolment Through K 12 Outreach Paper presented at 2004 Annual Conference, Salt Lake City, Utah. https://peer.asee.org/13573.

17. Workforce Imperative: A Manufacturing Education Strategy. (2010) Society of Manufacturing Engineers, available at http://www. sme.org/Workforceimperative, accessed Sept. 15, 2014.

18. National Science Foundation (2008). The Future of Materials Science and Materials Engineering Education A report from the Workshop on Materials Science and Materials Engineering Education sponsored by the National Science Foundation September 18-19, 2008 in Arlington, VA Accessed at https://www.nsf.gov/mps/dmr/mse_081709.pdf.

19. Nadelson, L., Moll, A., Seifert, A.(2011). Living in a Materials World: Materials Science Engineering Professional Development for K-12 Educators, 2011 American Society of Engineering Education Annual Conference and Exposition.

20. Zeller (2015) accessed at http://www.barrystaff.com/manufacturing-in-ohio on Dec. 27, 2015.

21. Air Force Research Labs (AFRL) Website, http://www.wpafb.af.mil/afrl/rx/, Accessed Aug. 1, 2013.

22. Dayton Region Manufacturers Association (DRMA), http://www.daytonrma.org/, accessed Aug. 1, 2013.

23. Ohio Economic Development Information Network (2009), 2nd qtr. Quarterly Census of Employment \& Wages [ES202] data. Cleveland, $\mathrm{OH}$.

24. Greater Ohio website, http://greaterohio.org/blog/2009/09/16/ohio-hub-of-innovation-and-opportunity/, Accessed Aug. 1, 2009. 
25. U.S. Dept. of Commerce Report (2012), "The Competitiveness and Innovative Capacity of the United States." January, 2012. Available at: http://www.commerce.gov/americacompetes.

26. National Science Foundation, Research Experiences for Teachers accessed from www.NSF.gov on Jan. 15, 2012.

27. Committee on Public Understanding of Engineering Messages, National Academy of Engineering (2008), Changing the Conversation: Messages for Improving Public Understanding of Engineering, National Academies Press, ISBN978-0-309-11934-4.

28. National Academy of Engineering, (2013). Changing the Conversation, Messaging for Engineering: From Research to Action, available at http://www.engineeringmessages.org/ , accessed Dec 21, 2015.

29. Rowley, J. Preiss, S., Pinnell, M, Franco, S., (2012). Engineering Innovation and Design for STEM Teachers and the STEM Quality Framework. Conference Proceedings, Published, P-12 Engineering and Design Summit, Washington DC, April 2012.

30. Pinnell, M., et. al, (2013). Bridging the Gap Between Engineering Design and PK-12 Curriculum Development Through the use the STEM Education Quality Framework, Journal of STEM Education, 14:4 available at http://ojs.jstem.org/index.php?journal=JSTEM\&page=article\&op=view\&path\%5B\%5D=1804.

31. STEM Education Quality Framework website, http://stemframework.washingtonstem.org/, Accessed Sept. 2013.

32. Horizon, Inc. (1996). Local systemic change teacher survey for math and for science teachers. Retrieved from http://www.horizon-research.com/instruments/hri_instrument.php?inst_id=10

33. Huinker, D., Enochs, L. (1995). Mathematics teaching efficacy beliefs instrument (MTEBI). Milwaukee: University of Wisconsin, Center for Mathematics and Science Education Research.

34. Riggs, I., Enochs, L. (1990). Toward the development of an elementary teacher's science teaching efficacy belief instrument. Science Education, 74, 625-63.

35. STEM Research Experiences for Teachers at the 2015 Forum: Next Generation STEM Learning for All, November 9, 2015, Washington D.C. (Next Generation STEM Learning for All Forum was the kick-off event for the November 10th White House Next Generation STEM High School Summit, an event organized by the WH Office of Science and Technology Policy, http://nsfstemforum.edc.org/related-press/).

36. DESS (2015). http://www.asmedayton.org/DESS/DESS.htm, accessed, Jan. 8, 2015. 